\title{
Processes and Outcomes of Theistic Spiritually Oriented Psychotherapy: A Practice-Based Evidence Investigation
}

\author{
Peter W. Sanders \\ Brigham Young University - Provo \\ P. Scott Richards \\ Brigham Young University - Provo, scott_richards@byu.edu \\ Jason A. McBride \\ Brigham Young University - Provo \\ Troy Lea \\ Brigham Young University - Provo \\ Randy K. Hardman

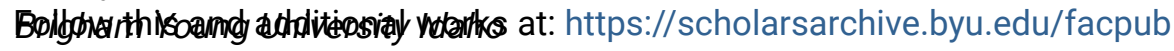 \\ Part of the Student Counseling and Personnel Services Commons
}

See next page for additional authors

Original Publication Citation

Sanders, P. W., Richards, P. S., McBride, J. A., Lea, T., Hardman, R. K., Barnes, D. V. (2015).

Processes and outcomes of theistic spiritually oriented psychotherapy: A practice-based evidence investigation. Spirituality in Clinical Practice, 2 (3), 180-190.

\section{BYU ScholarsArchive Citation}

Sanders, Peter W.; Richards, P. Scott; McBride, Jason A.; Lea, Troy; Hardman, Randy K.; and Barnes, Daniel V., "Processes and Outcomes of Theistic Spiritually Oriented Psychotherapy: A Practice-Based Evidence Investigation" (2015). Faculty Publications. 3843.

https://scholarsarchive.byu.edu/facpub/3843

This Peer-Reviewed Article is brought to you for free and open access by BYU ScholarsArchive. It has been accepted for inclusion in Faculty Publications by an authorized administrator of BYU ScholarsArchive. For more information, please contact ellen_amatangelo@byu.edu. 


\section{Authors}

Peter W. Sanders, P. Scott Richards, Jason A. McBride, Troy Lea, Randy K. Hardman, and Daniel V. Barnes 


\title{
Processes and Outcomes of Theistic Spiritually Oriented Psychotherapy: A Practice-Based Evidence Investigation
}

\author{
Peter W. Sanders, P. Scott Richards, \\ Jason A. McBride, and Troy Lea \\ Brigham Young University
}

\author{
Randy K. Hardman and Daniel V. Barnes \\ BYU Idaho Counseling Center, Rexburg, Idaho
}

\begin{abstract}
Various approaches for incorporating spirituality into psychotherapy have been developed, but few have been submitted to empirical scrutiny. The present article reports the results of a practice-based evidence (PBE) study, and demonstrates the value of PBE as a research strategy for the empirical evaluation of spiritually oriented psychotherapies (SOPs). This approach involves examining the effectiveness of SOPs in routine settings, providing more externally valid results than randomized controlled trials. Outcome and process data for 304 clients at a private, religious, university counseling center were examined using a PBE methodology. Clinicians integrated a wide variety of spiritual interventions with various secular treatments. The therapist, low initial spiritual distress, and client desire to discuss spirituality in session predicted the frequency with which spiritual interventions were used. The results of multiple hierarchical linear models suggested that clients improved substantially in multiple domains of functioning. The frequency of use of spiritual interventions was not a significant predictor of differential growth trajectories for clients. This study provides an example of how PBE can be used to explore and evaluate the effectiveness of the types of spiritual interventions practitioners employ in their practices.
\end{abstract}

Keywords: psychotherapy, spirituality, practice, evidence, religion

Despite the proliferation of spiritually oriented psychotherapies (SOPs) during the past two decades in the mental health professions, more process and outcome research is needed to establish a stronger evidence base for these approaches (Richards \& Worthington, 2010; Worthington, Hook, Davis, \& McDaniel, 2011). In harmony with the empirically supported treatments philosophy of evidence-based practice (EBP), many have called for an increased focus on establishing the efficacy of specific SOPs for specific disorders through randomized con-

Peter W. Sanders, P. Scott Richards, Jason A. McBride, and Troy Lea, Department of Counseling Psychology, Brigham Young University; Randy K. Hardman and Daniel V. Barnes, BYU Idaho Counseling Center, Rexburg, Idaho.

Supported by the John Templeton Foundation and the David O. McKay School of Education, Brigham Young University.

Correspondence concerning this article should be addressed to P. Scott Richards, Department of Counseling Psychology, 340 MCKB, Brigham Young University, Provo, UT 84602. E-mail: scott_richards@byu.edu trolled trials (RCTs; Chambless, Babich, \& Crits-Christoph, 1995; Hook et al., 2010; Worthington et al., 2011). Within the SOP literature, this approach involves examining the efficacy of specific SOPs or spiritual versions of mainstream treatments (i.e., Christian accommodative cognitive-behavioral therapy) for specific disorders, and comparing the outcomes of the SOP with bona fide secular treatment modalities or control groups. Ideally, this method would allow for highly controlled studies, in which the causal relationship between the use of SOPs and client improvement could be studied with minimal disturbance from potential confounds.

The use of RCTs provides important evidence for the efficacy of SOPs, but requires strict controls that may not be realistic in routine practice. In RCTs for psychotherapy, participants are generally selected that meet criteria for the disorder (or specific combinations of disorders) that is being targeted by the treatment in the study (Westen, Novotny, \& ThompsonBrenner, 2004). In this process, participants with diagnoses not the target of the study are 
excluded, because the nontargeted diagnosis could represent a confounding variable that would compromise the internal validity of the study. Additionally, RCTs generally use treatment manuals to ensure that the specific ingredients of the treatment are administered in a standardized manner (Chambless et al., 1998). This allows investigators to have more confidence in claims they make about the treatment, because the clinicians in the study are more likely to be using the treatment as it was intended to be administered. These aspects of RCTs make for studies with high internal validity, but potentially compromise the external validity of the studies due to the artificial nature of the trials.

In contrast, clinicians in routine practice do not have the luxury of only treating clients with a single diagnosis, and frequently integrate various treatment modalities to respond to their clients' needs (Westen et al., 2004; Stiles, 2013). This raises the question whether the SOPs used in routine practice are evidencebased, even if they incorporate aspects of empirically validated treatments. The possibility of conducting multiple RCTs for each possible combination of disorders with every possible type of eclectic treatment modality is a daunting prospect in terms of the time and monetary resources required to perform such research. Even if it could be done, it may still not reflect treatment as performed by therapists.

To make outcome research more relevant to clinical practice, a methodology called practice-based evidence (PBE) was developed (Barkham, Hardy, \& Mellor-Clark, 2010; Castonguay, Barkham, Lutz, \& McAleavey, 2013). This methodology moves away from exclusive reliance on RCTs to provide support for the efficacy of psychotherapy, and emphasizes performing studies in the context of routine practice. From this perspective, the focus is no longer on validating specific treatment packages for specific disorders, but, instead, attempts to see whether treatment as usual provides benefits to the types of clients seen at a specific treatment site by specific therapists. This approach is in line with the American Psychological Association's (APA) official stance on EBP, which encourages practice-based studies and the evaluation of outcomes in routine practice (APA Presidential Task Force on Evidence-Based Practice, 2006). One major advantage of this approach is that it allows for the study of the effectiveness of SOP, even if the therapist is not using a manualized treatment or is only treating clients with specific disorders. Thus, the work of the specific therapists is what is being studied, instead of the treatment modality as a whole, creating a more bottom-up approach to EBP (Barkham et al., 2010). PBE also allows clinicians to be involved in the formulation of research questions relevant to their clinical or administrative needs, increasing the likelihood that the research will have an impact on practice. PBE and RCTs are not mutually exclusive, but have the potential to answer different questions and to examine the outcomes and processes of psychotherapy from different perspectives (Barkham et al., 2010).

Another advantage of using a PBE approach is that it allows for gathering descriptive data about what kinds of SOPs therapists are using in their routine practice (Stiles, Barkham, MellorClark, \& Connell, 2008). Although the SOP literature is replete with theories of treatment, for the most part, little is known about how clinicians incorporate spirituality into their routine treatment. Additionally, little is known about when therapists decide to use spiritually oriented interventions and with which types of clients. With the assessment tools developed by the Bridges group (Richards, Sanders, Lea, McBride, \& Allen, 2015), in-depth descriptive analysis of what therapists are doing to adapt their treatment to the spiritual needs of clients is possible. With the tracking of both process and outcome data on a session-by-session basis, both can be linked together to examine the efficacy of specific processes or spiritual adaptations. This would provide evidence for the specific variations of treatment that individual clinicians are using, instead of whole treatment packages that are unlikely to be used in their purest forms.

The primary purpose of the current study was to demonstrate how the PBE method could be applied to SOP to examine several questions:

1. How effective are the SOP approaches practiced at Brigham Young University-Idaho's (BYU-I) counseling center?

2. What clinical issues and problems were treated? 
3. Which spiritual approaches and specific interventions were used during the course of treatment?

4. Did increased usage of spiritual interventions correspond to greater improvement for clients?

5. What factors predicted increased use of spiritual interventions?

The answers to these questions will give both researchers and clinicians the opportunity to see a concrete example of how a PBE approach to the study of SOPs can strengthen the evidence base for the use of SOPs in clinical practice. It will also provide evidence of the utility of the CAMOS (Clinically Adaptive Multidimensional Outcome System) system for investigating questions related to the processes and outcomes of SOPs at an aggregate, treatment center level.

\section{Method}

\section{Participants}

Clients. Three hundred four BYU-I student clients who sought services at the counseling center participated in the study. These 304 students received a total of 962 counseling sessions from the seven psychotherapists who participated in the study. Clients' average age was 21.8 years (range: 17-57). One hundred eightysix clients $(61.2 \%)$ were female; $116(38.2 \%)$ were male. Three hundred clients $(98.7 \%)$ were members of the Church of Jesus Christ of Latter-day Saints (LDS). Two hundred thirty-two $(76.3 \%)$ were White and 24 (7.9\%) were Latino/a, with other ethnicities representing less than $5 \%$ of the sample.

The psychotherapists diagnosed the clients with a variety of psychological problems. The therapists assigned diagnoses to $215(71 \%)$ clients, of which, 118 (54\%) were given at least two diagnoses. The most frequent diagnoses were major depression $(n=106)$, generalized anxiety disorder $(n=72)$, impulse control disorder $(n=23)$, eating disorder $(n=20)$, adjustment disorder $(n=18)$, obsessive-compulsive disorder $(n=15)$, posttraumatic stress disorder $(n=14)$, and bipolar disorder $(n=$ 10). Approximately $94 \%$ of the clients indicated that religion and/or spirituality is important in their lives, $88.8 \%$ indicated they would like to discuss religious and spiritual issues during counseling if it seemed relevant to their problems, $20.8 \%$ indicated that they felt religion has hurt them or contributed to some of their challenges, and $95.6 \%$ said they were willing to try religious or spiritual suggestions from their counselor if it appeared that this could be helpful.

Psychotherapists. Each psychotherapist who participated in the study was known to be experienced in providing theistic SOP. Each had a doctoral degree in counseling or clinical psychology or a master's degree in mental health counseling, and all were licensed providers. The therapists were an experienced groupthey had been providing psychotherapy for between 6 and 35 years.

\section{Procedures of the Study}

Data collection for the study began on March 11, 2013, and ended on February 28, 2014. Before data collection began, researchers provided training to therapists and office staff on study procedures, including (a) protecting client anonymity and confidentiality and (b) administering the measures in a standardized manner, (c) obtaining informed consent and demographic information from clients, (d) administering the weekly client outcome measures, and (e) completing the therapist session summary checklist.

When clients presented for treatment for their first session, a receptionist informed them that a research study was being done to assess the outcomes of treatment. The receptionist gave each potential participant a copy of the client informed consent document, which provided more information about the study and about the fact that participation was voluntary. Clients who agreed to participate in the study were asked to sign the informed consent document, and the receptionist showed them how to complete the assessment measures. All measures were completed electronically by clients using Amazon Kindle Fire tablets.

\section{Outcome and Process Measures}

All clients completed a brief intake questionnaire that requested information about their age, gender, and religious affiliation. Additionally, clients responded to four questions that inquired about the importance of spirituality in their life, 
and if they would be willing to have a spiritual component included in therapy (results are shown above in the "Clients" section). At the beginning of each therapy session, clients completed the Theistic Spiritual Outcome Survey (TSOS), a 17-item questionnaire (2-3 min) that assesses clients' perceptions of their spirituality from a theistic perspective, including their closeness to God, love for other people, and feelings of moral congruence and self-acceptance (Richards et al., 2005).

Before each session, clients also completed the Clinically Adaptive Client Outcome Measure (CA-COM; McBride, 2015; Richards, Sanders, McBride, \& Lea, 2014; Sanders, 2015), which is an adaptive measure that assesses based on clients' most salient concerns in up to six clinically relevant dimensions, including Clients' Perceptions of Their Spiritual Distress, Physical Health Distress, Relationship Distress, Psychological Distress, Work/School Distress, and Therapy Progress. The CA-COM did not require clients to complete all items each session-only those items that were most salient to their concerns. Because these data were gathered prior to the studies that determined the factor structure of the CA-COM (McBride, 2015; Sanders, 2015), we used only one item in our analyses to represent the Spiritual Distress, Relationship Distress, Physical Health Distress, Work/School Distress, and Therapy Progress dimensions. Consistent with the findings of McBride's (2015) study, we calculated a Psychological Distress dimension by combining the intake items from the Distressing Thoughts, Distressing Behaviors, and Distressing Emotions dimensions. At the conclusion of each therapy session, psychotherapists completed the CAMOS-Therapist Session Checklist (CATSC; Richards et al., 2014) to document which therapeutic issues were explored and which interventions used during the session (1-2 min).

\section{Data Analysis}

At the conclusion of the research study, the data were analyzed in several ways. First, data from the weekly CA-TSC completed by therapists was summarized and used to describe the range and type of theistic spiritual treatment interventions used throughout treatment and across the first eight sessions of treatment. Second, the percentage of sessions in which at least one spiritual intervention was used for each client was regressed on TSOS total score at intake, therapist, and whether the client was willing to try spiritual suggestions or advice. This model provided information about which factors might lead therapists to use spiritual interventions. This type of data analysis was only possible because we had CA-COM and TSOS outcome data, as well as the session-bysession CA-TSC process data.

Third, hierarchical linear modeling (HLM) was used to determine whether the interventions used by the counseling center therapists led to improvement in client psychological (CACOM) and spiritual (TSOS) outcomes across time. Given this procedure's ability to accommodate missing data, it represents a substantial improvement over analysis of variance-based repeated-measure analyses (Heck, Thomas, \& Tabata, 2013). Additionally, HLM was also used to examine whether the percentage of sessions in which spiritual interventions were used was predictive of variance between client slopes on the TSOS total score and all CA-COM scores. All HLM models were performed in SPSS, Version 23, and used restricted maximum likelihood estimation. Finally, effect sizes were computed based on the means of Sessions 1 and 8 in order to provide estimates of the magnitude of change during the first eight treatment sessions on the CA-COM and TSOS.

\section{Results}

\section{Aggregate Process Findings}

Therapists reported discussing concerns in several domains with their clients, as can be seen in Table 1. As would be expected, therapists spent the greatest amount of time in their sessions exploring clients' distressing emotions (66.8\% of sessions), distressing thoughts (63.9\% of sessions), and relationship concerns $(62.2 \%)$. Of particular interest was the finding that therapists discussed spiritual/religious concerns with $49 \%$ of clients and in approximately one third of sessions (33\%), suggesting that these concerns were salient for many clients and that the therapists in this sample were addressing them. The session-by-session percentages reveal that the frequency with which the various concerns were discussed remained quite stable across the first eight session of treatment, al- 
Table 1

Frequency of Topics Discussed by Session

\begin{tabular}{|c|c|c|c|c|c|c|c|c|c|}
\hline \multirow[b]{2}{*}{ Topic } & \multicolumn{8}{|c|}{ Session number } & \multirow[b]{2}{*}{ All } \\
\hline & 1 & 2 & 3 & 4 & 5 & 6 & 7 & 8 & \\
\hline Religious/spiritual concerns & $30 \%$ & $33 \%$ & $32 \%$ & $30 \%$ & $35 \%$ & $31 \%$ & $29 \%$ & $30 \%$ & $33 \%$ \\
\hline Physical health concerns & $7 \%$ & $10 \%$ & $8 \%$ & $5 \%$ & $10 \%$ & $14 \%$ & $15 \%$ & $0 \%$ & $8 \%$ \\
\hline Relationship concerns & $57 \%$ & $60 \%$ & $57 \%$ & $64 \%$ & $67 \%$ & $67 \%$ & $65 \%$ & $73 \%$ & $62 \%$ \\
\hline Self-defeating behaviors & $39 \%$ & $36 \%$ & $35 \%$ & $33 \%$ & $32 \%$ & $36 \%$ & $38 \%$ & $30 \%$ & $37 \%$ \\
\hline Distressing thoughts & $73 \%$ & $61 \%$ & $58 \%$ & $64 \%$ & $58 \%$ & $64 \%$ & $50 \%$ & $52 \%$ & $64 \%$ \\
\hline Distressing emotions & $82 \%$ & $62 \%$ & $63 \%$ & $64 \%$ & $62 \%$ & $62 \%$ & $53 \%$ & $61 \%$ & $67 \%$ \\
\hline Work concerns & $16 \%$ & $20 \%$ & $17 \%$ & $20 \%$ & $20 \%$ & $19 \%$ & $15 \%$ & $22 \%$ & $18 \%$ \\
\hline Therapy progress concerns & $4 \%$ & $2 \%$ & $3 \%$ & $5 \%$ & $8 \%$ & $2 \%$ & $9 \%$ & $0 \%$ & $5 \%$ \\
\hline Eating issues & $10 \%$ & $9 \%$ & $8 \%$ & $9 \%$ & $12 \%$ & $10 \%$ & $18 \%$ & $13 \%$ & $10 \%$ \\
\hline
\end{tabular}

though the frequency that distressing thoughts and distressing emotions were discussed declined somewhat over time.

The CA-TSC data also gave insight into what types of therapeutic orientations the counselors used most often in their work with clients. The most frequently used therapeutic approaches included cognitive-behavioral therapy (56\% of sessions), theistic-spiritual therapy consistent with LDS perspectives (50\% of sessions), strategic-structural-systemic approaches $(25 \%$ of sessions), interpersonal therapy (17\% of sessions), person-centered (9\% of sessions), and existential-humanistic (7\% of sessions). Although the aforementioned were the most common, clinicians at this treatment site used several other orientations (family therapy, rational-emotive-behavior therapy, psychodynamic), and most of them integrated several approaches in their work even within single sessions.

Finally, the CA-TSC data also gave insight into the spiritual interventions the counselors used with their clients, as shown in Table 2. The most frequently used spiritual interventions included praying silently for clients $(53 \%$ of sessions), teaching spiritual concepts ( $42 \%$ of sessions), teaching clients to listen to their hearts or spiritual impressions (27\%), and accepting God's love $(23 \%)$. Ninety percent of clients received a spiritual intervention in at least one session during their treatment, with just over $50 \%$ of clients receiving at least one spiritual intervention during all of their sessions, and $77 \%$ of clients received a spiritual intervention in over half of their sessions. The session-bysession percentages reveal that the frequency with which the various spiritual interventions

Table 2

Frequency of Spiritual Interventions by Session

\begin{tabular}{|c|c|c|c|c|c|c|c|c|c|}
\hline \multirow[b]{2}{*}{ Topic } & \multicolumn{8}{|c|}{ Session number } & \multirow[b]{2}{*}{ All } \\
\hline & 1 & 2 & 3 & 4 & 5 & 6 & 7 & 8 & \\
\hline Therapist silent prayer & $39 \%$ & $46 \%$ & $50 \%$ & $57 \%$ & $70 \%$ & $67 \%$ & $65 \%$ & $61 \%$ & $53 \%$ \\
\hline Teaching spiritual concepts & $32 \%$ & $36 \%$ & $46 \%$ & $44 \%$ & $48 \%$ & $55 \%$ & $56 \%$ & $52 \%$ & $42 \%$ \\
\hline Listening to the heart & $13 \%$ & $22 \%$ & $26 \%$ & $34 \%$ & $42 \%$ & $41 \%$ & $27 \%$ & $39 \%$ & $27 \%$ \\
\hline Accept God's love & $8 \%$ & $22 \%$ & $24 \%$ & $23 \%$ & $30 \%$ & $24 \%$ & $38 \%$ & $30 \%$ & $23 \%$ \\
\hline Encouraged trust in God & $8 \%$ & $11 \%$ & $10 \%$ & $14 \%$ & $18 \%$ & $24 \%$ & $18 \%$ & $22 \%$ & $15 \%$ \\
\hline Affirmed divine worth & $10 \%$ & $13 \%$ & $13 \%$ & $14 \%$ & $15 \%$ & $14 \%$ & $18 \%$ & $13 \%$ & $14 \%$ \\
\hline Discussed scriptures & $10 \%$ & $16 \%$ & $9 \%$ & $12 \%$ & $17 \%$ & $10 \%$ & $3 \%$ & $22 \%$ & $12 \%$ \\
\hline Spiritual assessment & $31 \%$ & $9 \%$ & $3 \%$ & $5 \%$ & $0 \%$ & $5 \%$ & $15 \%$ & $0 \%$ & $11 \%$ \\
\hline Spiritual self-disclosure & $5 \%$ & $11 \%$ & $14 \%$ & $9 \%$ & $15 \%$ & $17 \%$ & $9 \%$ & $0 \%$ & $11 \%$ \\
\hline Encouraged forgiveness & $7 \%$ & $11 \%$ & $10 \%$ & $12 \%$ & $12 \%$ & $10 \%$ & $9 \%$ & $4 \%$ & $9 \%$ \\
\hline Encouraged service & $4 \%$ & $8 \%$ & $7 \%$ & $11 \%$ & $10 \%$ & $17 \%$ & $9 \%$ & $22 \%$ & $8 \%$ \\
\hline Encouraged personal prayer & $4 \%$ & $8 \%$ & $9 \%$ & $11 \%$ & $5 \%$ & $15 \%$ & $6 \%$ & $9 \%$ & $8 \%$ \\
\hline Spiritual confrontation & $5 \%$ & $5 \%$ & $6 \%$ & $7 \%$ & $12 \%$ & $2 \%$ & $9 \%$ & $4 \%$ & $7 \%$ \\
\hline
\end{tabular}


were used over the course of treatment varied somewhat by intervention. For example, the frequency with which therapists prayed silently for their clients, taught spiritual concepts, encouraged clients to listen to their heart or spiritual impressions, encouraged clients to accept God's love, and encouraged clients to trust in God all increased during the course of treatment. On the other hand, therapists primarily conducted spiritual assessments during the first and second sessions and rarely did so later in treatment.

A multiple regression was performed to examine possible predictors of differential usage of spiritual interventions with clients. The frequency of the usage of spiritual interventions for each client was regressed on therapist, initial TSOS total score, and whether the client endorsed a willingness to accept spiritual suggestions or advice from their therapist. All three predictors were found to be significant in the presence of each other, with therapist being the strongest predictor $\left(R^{2}=.12\right)$, initial TSOS total score being the second strongest $\left(R^{2}=\right.$ $.032, \beta=.179$ ), and willingness to receive spiritual advice/intervention being the least pre- dictive $\left(R^{2}=.013, \beta=.115\right)$. These results suggested that spiritual interventions were used more often with clients having higher initial TSOS scores and greater desire to have spirituality incorporated into their treatment, while controlling for the therapist. The model accounted overall for $16.5 \%$ of the variance of usage of spiritual interventions.

\section{Aggregate Treatment Outcomes on the CA-COM}

Outcome data were analyzed using HLM. Client scores were modeled with the session number representing the unit of time. Linear $\left(\pi_{1}=-.73, t=-12.6, p<.01\right)$, quadratic $\left(\pi_{2}=.05, t=8.0, p<.01\right)$, and cubic $\left(\pi_{3}=\right.$ $-.001, t=-6.6, p<.01$ ) slopes were all found to be significant predictors of CA-COM Psychological Distress score, indicating a nonlinear relationship between the passage of time and improvement in CA-COM scores. This suggested a trajectory with a strong initial decrease in scores, followed by more gradual decrease in scores for the remainder of treatment. Figure 1 shows the growth curve for the first 10 sessions

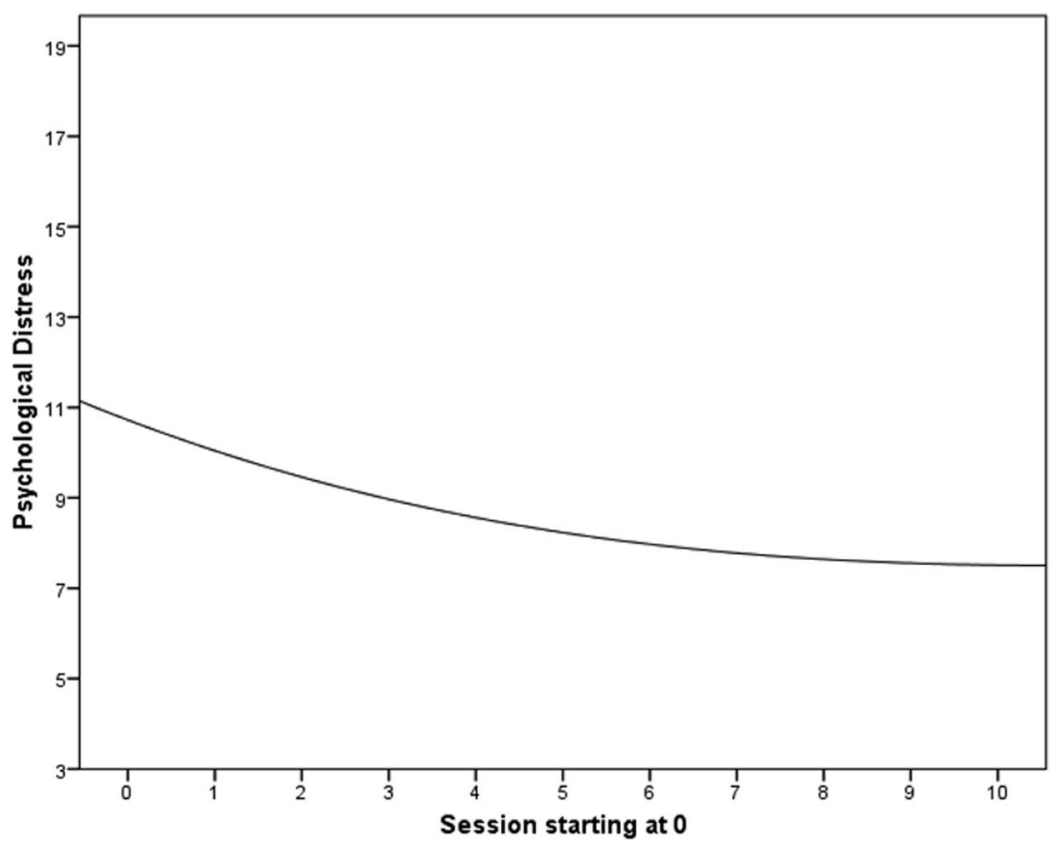

Figure 1. The Clinically Adaptive Client Outcome Measure Psychological Distress growth trend. 
of the CA-COM Psychological Distress dimension. The first 10 sessions were used because about $80 \%$ of the sample was seen for fewer than 10 sessions. All CA-COM dimensions had a similar cubic curve, although the degree of change varied between dimensions. Effect sizes were calculated using the mean values of Sessions 1 and 8 , because the majority of change occurred between these times, and because there still was a reasonably large sample size. The effect sizes (Cohen's $d$ ) for all CA-COM dimensions are as follows: Psychological Distress $(d=1.1)$, Relationship Distress $(d=$ 1.01), Therapy Progress $(d=.98)$, Work/ School Distress $(d=.86)$, Physical Health Distress $(d=.72)$, and Spiritual Distress $(d=.32)$. All dimensions except Spiritual Distress showed a medium to large effect size.

HLM was also used to examine the average growth trajectory of clients across time for the TSOS total score. A positive linear growth trajectory was significantly predictive of TSOS scores $(t=3.9, p<.01)$, with clients improving .22 points per session. This suggests small improvements in the TSOS scores (the pooled standard deviation across all sessions was 11.8). This could be the result of there being little room for improvement for the average client, because the model estimated the intercept to be 45.7, which suggests low levels of spiritual distress at intake (Richards et al., 2005). The effect size $(d)$ for the Sessions 1-8 TSOS total score means was .29. Figure 2 shows the first 10 sessions of the growth trajectory for the TSOS total score.

HLM was also used to examine whether increased frequency of spiritual interventions led to improved client outcomes. This involved using the percentage of sessions in which a spiritual intervention was used for each client (Level 2) and determining whether the interaction with time significantly predicted the slope for each dependent variable and time. None of these interactions was significant, suggesting that the frequency with which spiritual interventions was used did not predict differential growth trajectories for clients.

\section{Discussion}

This study provided an example of how the PBE research design could contribute to the development of an evidence base for SOP. In addition to demonstrating that the interventions

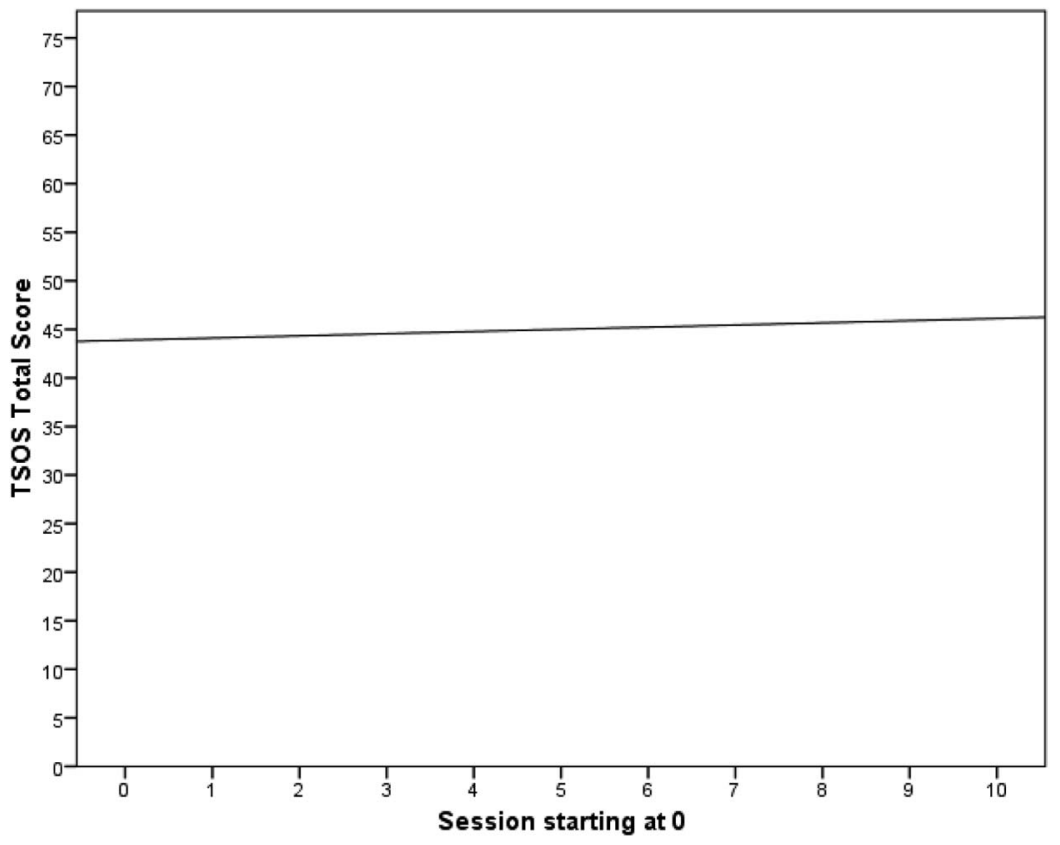

Figure 2. The Theistic Spiritual Outcome Survey total growth curve. 
used at BYU-I's counseling center were effective in aiding clients to decrease their psychological and spiritual distress and other dimensions of concern, the current study also provided descriptive data about what sorts of spiritual interventions were commonly used and what predicted their use. This study found that, at a counseling center where the majority of clients desired to have spirituality incorporated into their treatment, SOPs produced robust outcomes. It is also the first study to examine, at a session-by-session level, the spiritual interventions and topics of discussion therapists used. It was found that there was substantial variability in the theoretical orientations and spiritual interventions used, a finding that is consistent with survey studies that have asked therapists about the types of spiritual interventions they employ (e.g., Raphel, 2001; Richards \& Potts, 1995).

Additionally, the therapists treated clients with a broad range of diagnoses and used a variety of treatment modalities to ameliorate client distress. Many clients were given multiple diagnoses, suggesting that attempting to control for comorbid diagnoses would have excluded a good portion of the sample. The results presented here show that the therapists were generally effective across multiple diagnoses, although the analysis of growth trends for specific diagnoses was not performed. Therapists in this sample integrated a theistic/spiritual framework into approximately half of their sessions, and combined it primarily with cognitivebehavioral therapy, strategic-systemic therapy, and interpersonal therapy. This suggests that, even with different treatment approaches, spirituality can be integrated without compromising the efficacy of the treatment. This finding provides preliminary support for recommendations in the clinical literature that spiritual interventions can be integrated effectively with a variety of mainstream psychotherapy approaches (e.g., Richards \& Bergin, 2004, 2005; Sperry \& Shafranske, 2005).

The results of this study highlight the ability of PBE to provide research that more closely approximates the day-to-day realities of clinicians. The data were gathered with clients in a naturalistic setting, with many having multiple diagnoses, and receiving treatments that spanned various modalities. Thus, our study results have a high degree of external validity, in that they are more representative of the types of clients that clinicians will likely see, and the types of treatments they are likely to use than are tested in most RCTs. This study was particularly relevant to the treatment center at which it was performed, as it allowed therapists to demonstrate that their work was leading to measureable improvement in their clients. Additionally, given that BYU-I is owned and operated by the LDS Church, the finding that treatment at the counseling center was not undermining, but in fact improving clients' spiritual well-being, was important to document (Smith, Bartz, \& Richards, 2007). This is an example of how using practice-based research studies that reflect the contextual needs of treatment sites can benefit the treatment site itself as well as provide valuable data to build a stronger evidence base for SOP. This collaborative approach is the hallmark of the PBE philosophy of research (Castonguay et al., 2013).

The findings also demonstrate the utility and feasibility of CAMOS in gathering relevant practice-based research evidence. This study showed how findings from the CA-COM and the CA-TSC can provide much more in-depth information than is possible by just evaluating client-rated outcomes or processes. This represents an advance not only in evaluating the effectiveness of SOP, but also in PBE in general. Generally, PBE designs only capture client data in routine practice, which limits the types of questions that can be answered (Barkham et al., 2010). One potential concern with the use of a therapist checklist is that therapists would perceive it as an unnecessary time burden and not complete it. In the current study, however, therapists reported that the survey was quick and easy to complete, and that they did not perceive it as intrusive. They also reported finding information from the CA-COM was valuable in their work with clients, and that clients reported that it was not burdensome to complete it before each session. Future studies will need to examine whether these findings can be replicated in other treatment sites, because ensuring the feasibility of gathering routine outcome and process data is essential to successful implementation of these systems (Boswell, Kraus, Miller, \& Lambert, 2015).

The finding that the frequency of spiritual interventions did not significantly predict differential growth trajectories on any of the outcome 
variables was unexpected. One possible explanation for the lack of predictive power of the spiritual intervention variables may be the lack of variance in use of the interventions. Spiritual interventions were used with approximately $90 \%$ of clients at least once throughout the course of treatment, and in over half of the sessions for approximately $77 \%$ of clients. Additionally, the sample size for clients at later sessions was relatively small, due to dropout or successful completion of treatment. This, combined with the low percentage of clients who received few or no spiritual interventions, would lead to a very small group of clients who did not receive spiritual treatment at later sessions. Also, it could be that certain spiritual interventions were more useful than others, or had more impact at certain times in treatment. The current study did not examine whether certain types of spiritual interventions were more predictive of improvement than other interventions, but such analyses would be possible using the CAMOS system with a larger data set.

Another possible reason for the lack of differential efficacy of spiritual interventions may be that there are inherent limitations in connecting process and outcome in routine practice, because responsiveness is an essential component of treatment (Stiles, 1988). Interventions are not just performed because research or treatment manuals state that they are generally effective at certain points, but are used in reaction to what the client does or says in therapy. Thus, simply abstracting the use of spiritual interventions from the context of client characteristics is unlikely to yield significant findings. From this perspective, more complex models examining the indirect effects of spiritual interventions through various processes such as the therapeutic alliance and other nonspecific treatment factors may be more fruitful (Wampold \& Imel, 2015).

The finding that higher initial TSOS scores and client desire for spiritual suggestions/advice were predictive of the frequency of spiritual interventions suggests that they were being used in a responsive manner. Given these findings, therapists may have used the spiritual interventions not specifically to ameliorate spiritual concerns, but to access the client's spirituality as a resource for healing their emotional problems. Thus, if a client had more resources (higher TSOS score and willingness to accept spiritual suggestions), then the spiritual interventions were more likely to be used. This approach would be consistent with religious coping models, which suggests that drawing on a client's religion or spirituality can be a way increasing his or her resilience to mental health problems (Pargament, Koenig, \& Perez, 2000; Sanders et al., 2015). Future studies should assess different groups of clients to examine in which groups use (or lack thereof) of spiritual interventions is most effective. Such analyses would be possible with larger data sets that could be obtained through the mass collaboration advocated by Richards et al. (2015).

\section{Limitations}

One limitation with this study is its sample size. To control properly for a wide variety of possible confounds, it is necessary to have large sample sizes. Because most clients in the sample left treatment after only a few sessions, relatively few clients remained in later sessions, making it difficult to have much statistical power in the conclusions. Also, most therapists used spiritual interventions with the majority of their clients, making comparisons between spiritual intervention and purely secular interventions difficult. In the current study, examining whether the spiritual interventions provided were differentially beneficial for clients with specific diagnoses was not possible, because there were too few exemplars in most diagnostic categories to be able to perform meaningful comparisons. Additionally, a larger sample size would allow for more nuanced analysis of which people benefited most from SOPs. It would also allow for the HLM to provide more accurate estimates of the growth curve at later sessions. The sample used in this study only included a few clients who received more than 10 sessions, thus we could not provide much information on longer term therapy. Additionally, the sample was composed almost exclusively of White LDS college students, which limits the generalizability of the study. Despite the sample limitations, this study did provide some useful information about the usage of spiritual interventions, and provided a model for future studies of the types of questions that the CAMOS outcome system could be used to address. 
Although this study demonstrated the strengths of a PBE approach, it also revealed the limitations inherent in such an approach (Barkham et al., 2010). Given that PBE studies do not use manuals or fidelity checks, there is complete reliance on patient and therapist report of their outcomes and processes. This is especially relevant with the CA-TSC, in which an individual spiritual intervention (i.e., teaching spiritual concepts) may in practice be very different from one therapist to the next. Therefore, definitions of the treatments are not standardized. Additionally, some have found that selfprofessed theoretical orientation often does not match the core tenets of the approach (Creed et al., 2014). This could call into question the finding that therapists used a variety of theoretical orientations, or could mean that more theoretical orientations were used than were documented in the study. Although this is problematic, some have claimed that even RCTs can encounter similar problems, and that standardization of treatment may not be realistic or beneficial (Wampold \& Imel, 2015; Stiles, 2013). Overall, PBE designs are not as internally valid as RCTs, but compensate for this by providing greater external validity.

\section{Conclusion}

For SOPs to gain greater acceptance in the mainstream of the field, more empirical support for these interventions is necessary. PBE provides a compelling alternative to traditional RCT-based approaches to EBP in that it focuses on generating research in the context of routine practice. The present study provided an example of how PBE can be used to evaluate the efficacy of SOP in a manner that is both nonintrusive and inexpensive. It was found that the SOPs delivered at BYU-I's counseling center were efficacious in improving a variety of psychological and spiritual outcomes for clients with a broad range of diagnoses. Additionally, use of client outcome data and therapist process data provided valuable information about the types of interventions that spiritually oriented therapists use and the reasons why they use them. This study only scratches the surface of what might be possible if practitioners and researchers can engage in large-scale collaboration using the CAMOS system through the Bridges Practice-Research Network (Richards et al., 2015). Such collaboration could be the key to providing an adequate evidence base to ensure that religious and spiritual clients receive treatments tailored to their worldviews.

\section{References}

APA Presidential Task Force on Evidence-Based Practice. (2006). Evidence-based practice in psychology. American Psychologist, 61, 271-285. http://dx.doi.org/10.1037/0003-066X.61.4.271

Barkham, M., Hardy, G. E., \& Mellor-Clark, J. (Eds.). (2010). Developing and delivering practice-based evidence: A guide for the psychological therapies. Malden, MA: Wiley-Blackwell. http:// dx.doi.org/10.1002/9780470687994

Boswell, J. F., Kraus, D. R., Miller, S. D., \& Lambert, M. J. (2015). Implementing routine outcome monitoring in clinical practice: Benefits, challenges, and solutions. Psychotherapy Research, 25, 6-19. http://dx.doi.org/10.1080/10503307 .2013 .817696

Castonguay, L., Barkham, M., Lutz, W., \& McAleavey, A. (2013). Practice-oriented research: Approaches and applications. In M. J. Lambert (Ed.), Bergin and Garfield's handbook of psychotherapy and behavior change (6th ed., pp. 85-133). Hoboken, NJ: John Wiley.

Chambless, D., Babich, K., \& Crits-Christoph, P. (1995). Training in and dissemination of empirically-validated psychological treatments: Report and recommendations. Clinical Psychologist, 48, $3-24$.

Chambless, D. L., Baker, M. J., Baucom, D. H., Beutler, L. E., Calhoun, K. S., Crits-Christoph, P., . . . Haaga, D. A. (1998). Update on empirically validated therapies, II. Clinical Psychologist, 51, 3-16.

Creed, T. A., Wolk, C. B., Feinberg, B., Evans, A. C., \& Beck, A. T. (2014). Beyond the label: Relationship between community therapists' self-report of a cognitive behavioral therapy orientation and observed skills. Administration and Policy in Mental Health and Mental Health Services Research. Advance online publication. http://dx.doi.org/10 .1007/s10488-014-0618-5

Heck, R. H., Thomas, S. L., \& Tabata, L. N. (2013). Multilevel and longitudinal modeling with IBM SPSS. New York, NY: Routledge.

Hook, J. N., Worthington, E. L., Jr., Davis, D. E., Jennings, D. J., II, Gartner, A. L., \& Hook, J. P. (2010). Empirically supported religious and spiritual therapies. Journal of Clinical Psychology, 66, 46-72.

McBride, J. A. (2015). Development of the Clinically Adaptive Client Outcome Measure (CA-COM): A 
factor analytic study (Unpublished doctoral dissertation). Brigham Young University, Provo Utah.

Pargament, K. I., Koenig, H. G., \& Perez, L. M. (2000). The many methods of religious coping: Development and initial validation of the RCOPE. Journal of Clinical Psychology, 56, 519-543. http://dx.doi.org/10 .1002/(SICI)1097-4679(200004)56:4<519::AIDJCLP6>3.0.CO;2-1

Raphel, M. M. (2001). The status of the use of spiritual interventions in three professional mental health groups. Dissertation Abstracts International: Section A: Humanities and Social Sciences, 62(2-A), 779.

Richards, P. S., \& Bergin, A. E. (Eds.). (2004). Casebook for a spiritual strategy in counseling and psychotherapy. Washington, DC: American Psychological Association. http://dx.doi.org/10 $.1037 / 10652-000$

Richards, P. S., \& Bergin, A. E. (2005). A spiritual strategy for counseling and psychotherapy (2nd ed.). Washington, DC: American Psychological Association. http://dx.doi.org/10.1037/11214-000

Richards, P. S., \& Potts, R. W. (1995). Using spiritual interventions in psychotherapy: Practices, successes, failures, and ethical concerns of Mormon psychotherapists. Professional Psychology: Research and Practice, 26, 163-170. http://dx.doi .org/10.1037/0735-7028.26.2.163

Richards, P. S., Sanders, P. W., Lea, T., McBride, J. A., \& Allen, G. E. K. (2015). Bringing spiritually oriented psychotherapies into the health care mainstream: A call for worldwide collaboration. Spirituality in Clinical Practice, 2, 169-179. http://dx.doi.org/10.1037/scp0000082

Richards, P. S., Sanders, P. W., McBride, J. A., \& Lea, T. (2014, August). Bridging the researchpractice gap with a clinically adaptive Internetbased outcome system. Paper presented at the annual convention of the American Psychological Association, Washington, DC.

Richards, P. S., Smith, T. B., Schowalter, M., Richard, M., Berrett, M. E., \& Hardman, R. K. (2005). Development and validation of the Theistic Spiritual Outcome Survey. Psychotherapy Research, 17, 457-469. http://dx.doi.org/10 .1080/10503300500091405

Richards, P. S., \& Worthington, E. L., Jr. (2010). The need for evidence-based, spiritually oriented psychotherapies. Professional Psychology: Research and Practice, 41, 363-370. http://dx.doi.org/10 $.1037 / \mathrm{a} 0019469$

Sanders, P. W. (2015). Development of short-form versions of the Clinically Adaptive Client Outcome
Measure (CA-COM) (Unpublished doctoral dissertation). Brigham Young University, Provo Utah.

Sanders, P. W., Allen, G. E., Fischer, L., Richards, P. S., Morgan, D. T., \& Potts, R. W. (2015). Intrinsic religiousness and spirituality as predictors of mental health and positive psychological functioning in Latter-Day Saint adolescents and young adults. Journal of Religion and Health, 54, 871887. http://dx.doi.org/10.1007/s10943-015-0043-4

Smith, T. B., Bartz, J., \& Richards, P. S. (2007). Outcomes of religious and spiritual adaptations to psychotherapy: A meta-analytic review. Psychotherapy Research, 17, 643-655. http://dx.doi.org/ 10.1080/10503300701250347

Sperry, L., \& Shafranske, E. P. (Eds.). (2005). Spiritually oriented psychotherapy. Washington, DC: American Psychological Association. http://dx.doi .org/10.1037/10886-000

Stiles, W. B. (1988). Psychotherapy process-outcome correlations may be misleading. Psychotherapy: Theory: Research, \& Practice, 25, 27-35. http:// dx.doi.org/10.1037/h0085320

Stiles, W. B. (2013). The variables problem and progress in psychotherapy research. Psychotherapy, 50, 33-41. http://dx.doi.org/10.1037/ a0030569

Stiles, W. B., Barkham, M., Mellor-Clark, J., \& Connell, J. (2008). Effectiveness of cognitivebehavioural, person-centred, and psychodynamic therapies in UK primary-care routine practice: Replication in a larger sample. Psychological Medicine, 38, 677-688. http://dx.doi.org/10.1017/ S0033291707001511

Wampold, B. E., \& Imel, Z. E. (2015). The great psychotherapy debate: The evidence for what makes psychotherapy work. New York, NY: Routledge.

Westen, D., Novotny, C. M., \& Thompson-Brenner, H. (2004). The empirical status of empirically supported psychotherapies: Assumptions, findings, and reporting in controlled clinical trials. Psychological Bulletin, 130, 631-663. http://dx.doi.org/ 10.1037/0033-2909.130.4.631

Worthington, E. L., Jr., Hook, J. N., Davis, D. E., \& McDaniel, M. A. (2011). Religion and spirituality. In J. C. Norcross (Ed.), Relationships that work (2nd ed., pp. 402-419). New York, NY: Oxford University Press. http://dx.doi.org/10.1093/acprof: oso/9780199737208.003.0020

Received July 28, 2015 Accepted July 29, 2015 